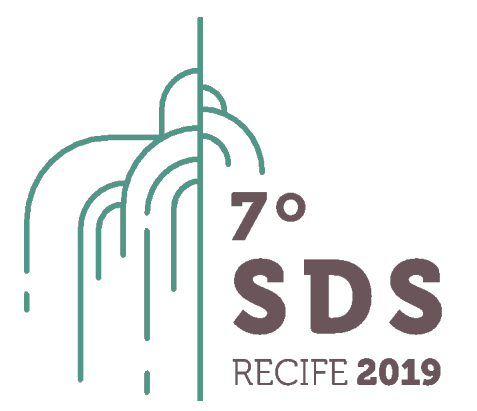

$\bar{S}$

SIMPÓSIO SUSTAINABLE

DESIGN DESIGN

SUSTENTÁVEL SYMPOSIUM

\title{
Feito à mão e pelo corpo: inovação social pelo design e pela dança
}

\author{
Anamaria Fernandes Viana ${ }^{1}$, Glaucinei Rodrigues Corrêa ${ }^{2}$, Jéssica Kawaguiski ${ }^{3}$, Júlia Carvalho Passos ${ }^{4}$ \\ ${ }^{1}$ Doutora, Universidade Federal de Minas Gerais, anamariafernandes160@gmail.com \\ ${ }^{2}$ Doutor, Universidade Federal de Minas Gerais, glaucinei@ufmg.br \\ ${ }^{3}$ Graduada, Universidade Federal de Minas Gerais, kawaguiski@hotmail.com \\ ${ }^{4}$ Graduanda, Universidade Federal de Minas Gerais, juliacarpassos@gmail.com
}

\begin{abstract}
This article discusses the Flores do Morro Extension Project: design, dance and architecture for social welfare, from the Federal University of Minas Gerais with Flores do Morro, which is a women's group from Morro das Pedras, a socially vulnerable area in the city of Belo Horizonte. The project develops creativity, improvisation and playful activities with the group members, not only to enrich their craft, but also to improve the participants self-esteem and strengthen group identity. The methodological procedures adopted in the project value the relationship between those involved in the process as well as recognizes the knowledge and potential of each participant. As main results, it is possible to highlight the dialogue interaction between the University and the community, the improvement of body consciousness of the participants, as well as the appreciation of their own work.
\end{abstract}

Keywords. design, dance, social innovation, sustainability, craft.

\section{Introdução}

O projeto de extensão "Flores do Morro: design, dança e arquitetura para o bem-estar social" teve início em 2018, como uma continuidade dos trabalhos desenvolvidos na disciplina de Design Social e no curso de Design da UFMG e na disciplina Poéticas do Tempo: dança e longevidade, no curso de Dança da UFMG. Ambas as disciplinas desenvolveram, em 2017, diversos trabalhos de Design e de Dança, de forma independente, com o grupo Flores do Morro, na comunidade do Morro das Pedras, região de vulnerabilidade social de Belo Horizonte.

O grupo, formado por aproximadamente 15 mulheres, surgiu em 2011 e manteve-se, até 2017, com verba pública municipal repassada ao Caritas Nossa Senhora de Fátima. Eram realizadas oficinas de bordado e pintura, com a finalidade de apoiar as participantes em suas diversas dificuldades pessoais. A partir de 2018, o grupo passou a ter o apoio somente das Pró-Reitorias de 
Extensão e de Graduação da Universidade Federal de Minas Gerais (UFMG), por meio de pagamento de bolsas para as estudantes participantes do projeto.

Portanto, o projeto surgiu para desenvolver e enriquecer o processo já iniciado com a comunidade de forma a integrar áreas do conhecimento. Além de estudantes dos cursos de Design e de Dança da UFMG, o projeto conta com uma bolsista do curso de Arquitetura e Urbanismo. Assim, a proposta é desenvolver com as mulheres, atividades que integram o design e o corpo em movimento no território em que o grupo está inserido. Para tal, as atividades são idealizadas sob as perspectivas dessas três áreas em conjunto.

Ao se trabalhar com um grupo exclusivamente feminino, experimenta-se, por meio das oficinas, maneiras de abrir vias de ação e acesso a alguns direitos que até hoje são vedados às mulheres, seja no trabalho, na sociedade ou no campo pessoal. Enfrenta-se diariamente desafios relacionados à autonomia e autoestima das integrantes do grupo, o que influencia diretamente na forma de fazer, no ritmo e no reconhecimento de cada uma em suas produções artísticas.

Assim, para além de ampliar o repertório artístico e técnico, o objetivo do projeto é trabalhar a autoestima, desenvolver a consciência corporal, as potencialidades de expressão criativa das participantes e fortalecer a identidade do grupo. Além disso, o projeto visa também o desenvolvimento da autonomia das participantes, a fim de se criar meios de sustentabilidade do trabalho, sem a dependência da Universidade. Por isso, percebe-se a importância da valorização dos saberes já existentes entre as mulheres, bem como a ampliação das possibilidades de produção e de geração de renda para o grupo.

\section{Inovação social e sustentabilidade}

Em relação à inovação social, Langenbach (2008) argumenta que há várias definições e conceitos sobre o tema e que, genericamente, pode ser compreendida como diversos casos à nossa volta, como os mutirões para construção de casas populares, dentre outros exemplos, os quais já foram inovadores socialmente e, hoje, fazem parte de um padrão estabelecido. Ainda, segundo o autor,

todos são exemplos de inovações sociais - novas ideias que buscam suprir as necessidades ainda não atendidas, de modo a melhorar a vida das pessoas. [...] Segundo essa concepção, as experiências inovadoras surgem às margens da sociedade e buscam um espaço para se fortalecerem, apontando tendências para o futuro (LANGENBACH, 2008, p. 13).

Corroborando com esse conceito, o Centro para Inovação Social (Centre for Social Innovation $)^{1}$ do Canadá, refere-se à inovação social como criação, desenvolvimento, adoção e integração de novos e renovados conceitos, sistemas e práticas que colocam as pessoas e o planeta em primeiro lugar.

Nessa mesma direção, Manzini aponta que

o termo inovação social refere-se a mudanças no modo como indivíduos ou comunidades agem para resolver seus problemas ou criar novas oportunidades. Tais inovações são guiadas mais por mudanças de comportamento do que por mudanças tecnológicas ou de mercado, geralmente emergindo através de processos organizacionais 'de baixo para cima' em vez daqueles 'de cima para baixo'. (MANZINI, 2008 p. 61-62)

\footnotetext{
${ }^{1}$ Link de acesso: $h$ ttpd://socialinnovation.org/, acesso em 7 fevereiro 2018.
} 
Desse modo, entende-se o caráter de inovação social do Flores do Morro, por combinar os saberes e experiências de cada uma das estudantes envolvidas, com os saberes das participantes e com os recursos disponíveis à mão, em um trabalho desenvolvido por um grupo organizado pela própria comunidade, em que o foco não está apenas no produto (como resultado), mas nos materiais e no processo de criação. Buscamos formas de produção, que não caiam no automatismo, que valorizem os modos tradicionais de fazer, associados a novos meios de aprendizagem. Assim, fortalecemos os laços e buscamos visibilidade para o projeto, não apenas pela confecção e venda dos produtos, mas também pela valorização das trocas diárias, seja numa roda de conversa, na execução de um ponto de crochê, nas criações em dança ou nos trabalhos com os elementos do bairro de forma afetiva, sempre respeitando o tempo de cada integrante.

Em relação à sustentabilidade ambiental dos produtos e seus ciclos de vida, priorizamos a criação a partir dos insumos disponíveis, reutilizando materiais que seriam descartados por empresas ou pequenos comerciantes - como retalhos de tecidos, garrafas pet, tampinhas de garrafa, jornais e embalagens de vidro - ou até mesmo, pelo próprio coletivo, como papéis utilizados, que podem ser transformados em embalagens. Quanto à sustentabilidade econômica, como mencionado anteriormente, o grupo já possuía uma dinâmica de trabalho anterior ao estabelecimento da parceria com a UFMG. Portanto, levou um tempo para entendermos as reais demandas das participantes, na tentativa de equilibrar os desejos individuais e as necessidades do coletivo. Assim, a questão da possibilidade de venda dos produtos surgiu aos poucos, à medida que as participantes percebiam a qualidade das suas produções, bem como a necessidade da compra de novos materiais.

Portanto, de acordo com critérios elencados por Sachs (1990, p.5), em prol do desenvolvimento sustentável, o projeto se propõe I) a ser includente do ponto de vista social, à medida que trabalha com mulheres em vulnerabilidade social, muitas delas idosas e/ou com deficiências e busca um engajamento de todas, de acordo com cada particularidade; II) a ser sustentável do ponto de vista ecológico, por buscar recursos locais e utilizar materiais que seriam descartados para a confecção dos produtos, e III) a ser sustentado do ponto de vista econômico, já que caminha para a geração de renda alternativa para o grupo (apud Krucken, 2009, p.75).

\section{Fundamentação Teórica}

Ainda tendo como base os pensamentos de Manzini sobre inovação social, levamos em consideração o que o autor chama de bem-estar ativo, "condição na qual somos ativos e cuidamos de nós mesmos, da nossa família, da vizinhança e do ambiente, pois gostamos dele" (MANZINI, 2008, p. 55), em que as capacidades, sensibilidades e espírito de iniciativa tem papel fundamental. Esse bem-estar está baseado não apenas no resultado do produto confeccionado, mas é um bemestar baseado no contexto, a partir de uma liberdade de ação e, sobretudo, no caso do Flores do Morro, se relaciona com o que as mulheres sabem, podem e desejam fazer. (MANZINI, 2008)

Dentre outros autores que nortearam nosso trabalho se encontram, principalmente, Paulo Freire (2016), educador, pedagogo e filósofo brasileiro; Sennett (2009), sociólogo e historiador norte americano e Klauss Vianna (2005), dançarino, professor e teórico de dança brasileiro.

Freire (2016) nos ajuda a repensar a prática relacionada ao processo de ensino e aprendizagem e nos instiga a desenvolver um verdadeiro interesse e curiosidade pelo outro, pelas suas histórias e vivências. $O$ objetivo é que as oficinas aconteçam de maneira a possibilitar a troca de saberes entre as estudantes, os professores e as mulheres participantes do grupo, na tentativa de desconstruir essa relação tradicional professor-aluno. Assim, as estudantes levam propostas de design e dança, mas também aprendem técnicas com as participantes do grupo, como alguns pontos de bordado e crochê, e as ideias para os produtos surgem, frequentemente, por meio 
dessa troca.

A constante busca pela não hierarquização dos conhecimentos faz com que haja uma maior aproximação entre os sujeitos envolvidos no processo e, como os temas trabalhados estão diretamente ligados às vivências pessoais, às memórias de infância e ao corpo, as oficinas dependem da abertura e da disposição de todas em compartilhar, o que é muito desafiador, tanto para as mediadoras quanto para as participantes. Portanto, o trabalho desenvolvido recusa a experiência educativa como um simples treinamento técnico, se alinha ao pensamento de que "ensinar não é transferir conhecimento" (FREIRE, 2016), e se propõe a criar possibilidades de construção de um saber coletivo. Isso propicia trocas pessoais muito verdadeiras e relevantes, mas requer uma autoanálise e autocrítica constantes, que compartilhamos em reuniões frequentes.

Outro autor que nos permite pensar e refletir nossas práticas é Richard Sennett. O sociólogo defende a não separação entre o fazer e o pensar, e que "[...] as habilidades até mesmo as mais abstratas, tem início como práticas corporais." (SENNETT, 2009, p. 20-21). Esse pensamento, que propõe uma superação da dicotomia entre corpo e mente, nos é muito rico em um ambiente que integra mulheres - muitas delas que não tiveram estudo formal, mas praticaram esse "pensar com as mãos" durante toda a vida - e professores e estudantes da universidade, que nesse contexto, são convidados a saírem da zona teórica para atuar na realidade da comunidade em que se inserem.

Além disso, o ato de fazer com as mãos leva a um pensar sobre si mesmo e pode mobilizar habilidades necessárias nas relações humanas, o que acaba por enriquecer as trocas com o grupo. Segundo o autor:

[...] O ofício de produzir coisas materiais permite perceber melhor as técnicas de experiência que podem influenciar nosso trato com os outros. Tanto as dificuldades quanto as possibilidades de fazer bem as coisas se aplicam à gestão das relações humanas. Desafios materiais como enfrentar uma resistência ou gerir ambiguidades contribuem para o entendimento das resistências que as pessoas enfrentam na relação com as outras ou dos limites incertos entre as pessoas (SENNETT, 2009, p. 322- 323).

Assim, as habilidades sugeridas pelo trabalho artesanal refletem na vida cotidiana e nas relações pessoais. Por isso, o ambiente criado no projeto - de desenvolvimento da consciência das habilidades em produzir e criar - facilita o surgimento de aptidões que se aplicam à vida social e propicia o empoderamento e a postura mais autônoma das participantes.

Sobre as contribuições de Klauss Vianna (2005) para as escolhas realizadas no projeto, assim como Sennet (2009), o artista também recusa hierarquias entre mente e corpo para dizer sobre experiências de dança. Em sua obra autobiográfica, Vianna procura organizar conhecimentos construídos ao longo de vivências artísticas e avaliar criticamente os processos de formação percorridos ao longo de sua história. A partir de então, ele propõe uma abordagem mais viva e menos instrumentalizada para a experiência educativa em dança, que valorize as relações experimentadas pelos sujeitos em detrimento da transmissão de formas prontas para o movimento. Segundo ele, o surgimento do novo pode se fazer presente mesmo em procedimentos de repetição, desde que exista espaço para os movimentos de troca com o mundo, espaço para o exercício da escuta. Segundo ele, dançar "não significa reproduzir apenas formas. A forma pura é fria, estática, repetitiva. Dançar é muito mais aventurar-se na grande viagem do movimento que é a vida" (VIANNA, 2005, p. 112). Com essa afirmação, ele não pretende descartar a validade de procedimentos técnicos e sistematizações para a criação, mas recolocá-los de acordo com a sua utilidade:

Há uma mentalidade predominante que concebe a técnica como um fim em si, quando na verdade ela deve ser mais um meio eficaz e em plena sintonia com os fins que proponho atingir. E a técnica eficaz talvez seja aquela que torna possível extrapolar todos os falsos e 
repetitivos conceitos de beleza, que permite criar ou revelar a identidade entre a dança e o dançarino, entre quem dança e o que está sendo dançado (VIANNA, 2005, p. 113).

Como caminho possível para a construção de experiência de criação mais significativa, que potencialize os movimentos de autoconhecimento e expressividade dos sujeitos, Vianna insiste na valorização dos processos: "Todo processo criativo é quase sempre marcado por contradições e antagonismos constantes, em que nascimento, vida e morte, alegria, prazer e dor constituem momentos distintos, que se confundem e dão sentido a uma nova existência" (VIANNA, p.100).

\section{Metodologia}

Por meio de oficinas, ocorridas duas vezes por semana, propomos uma dinâmica de trabalho diferente do modelo de aulas expositivas ou práticas pré-formatadas e nos colocamos em posição de diálogo e troca com as participantes. Desse modo, a relação construída é de proximidade entre os sujeitos, reconhecimento e valorização dos conhecimentos e das potencialidades de cada integrante. Ouvindo os sujeitos ali presentes e trabalhando de forma colaborativa, entendemos o que aquela comunidade necessita e deseja, para então desenharmos de fato algo, analisando a praticabilidade e viabilidade do projeto ${ }^{2}$.

Incentivamos uma postura de autonomia do grupo de forma geral e, para tal, organizamos diversos tipos de atividades para que as participantes se engajem nas questões práticas, como uma espécie de "leilão" fictício para pensarmos coletivamente a precificação; dinâmicas para a separação de retalhos de tecido, para a contabilidade e organização dos materiais e incentivamos a contribuição com materiais recicláveis a serem empregados nos produtos. Além disso, a própria elaboração criativa, por ser uma ferramenta de participação ativa na vida cultural, na medida em que o sujeito interfere e é modificado pela realidade, facilita trocas afetivas e o estabelecimento de vínculos entre as participantes e o ambiente. Além disso, promove uma postura geral mais ativa das mulheres. Como sugere Freire

O fato de me perceber no mundo, com o mundo e com os outros me põe numa posição em face do mundo que não é de quem nada tem a ver com ele. Afinal, minha presença no mundo não é a de quem a ele se adapta, mas a de quem nele se insere. É a posição de quem luta para não ser apenas objeto, mas sujeito também da historia (FREIRE, 2016, p. 53).

O grande desafio inicial foi pensar formas de se trabalhar as três áreas de conhecimento (Design, Dança e Arquitetura) de modo realmente integrado. O fazer manual e o gesto com o corpo, foram ferramentas que facilitaram a inserção destas atividades com as participantes. Portanto, decidimos elencar alguns temas que poderiam fazer essa ligação, de acordo com as demandas e com a realidade do grupo. Tais atividades, contaram com duas etapas importantes; a primeira delas, foi um momento processual, relacionado ao trabalho de base, introdução e experimentação e o segundo momento foi o de elaboração de produtos.

Durante a etapa processual, que se estendeu ao longo do primeiro semestre de 2018, foram estudados, das mais diversas maneiras, conceitos de design como cor, forma e composição, sem ter em mente um produto como objetivo. Foi o que possibilitou uma maior aproximação com a dança, à medida que tais conceitos eram trabalhados com o corpo em movimento no espaço, de forma mais espontânea e sensorial. Em muitos momentos, não era possível distinguir a atividade realizada como sendo apenas de design ou de dança, as áreas eram exploradas de forma conjunta.

A etapa de elaboração de produtos, que começou no segundo semestre de 2018 e se

\footnotetext{
2 Conceitos abordados no HCD Ideo Toolkit, 2009. Disponível em: <https://hcd-connectproduction.s3.amazonaws.com/toolkit/en/portuguese_download/ideo_hcd_toolkit_complete_portuguese.pdf > Acesso em 29 de Março de 2019.
} 
estende até o momento, também foi e tem sido desafiadora. Tivemos de lidar com as expectativas de materiais "bem-acabados" e experimentar diferentes tipos de produtos para entender o que funcionaria melhor no contexto de produção em um grupo muito heterogêneo e com limitações físicas e motoras diversas. O trabalho começou a fluir melhor quando percebemos que poderíamos ter atividades processuais em um momento da oficina e aplicar os conceitos trabalhados em um segundo momento, nos produtos. Além disso, outro ponto que contribuiu para o desenvolvimento dos produtos foi a aposta na autoria coletiva, a partir da qual as mulheres passaram a se dividir nas etapas de produção de acordo com seus desejos, interesses e limites.

O desenvolvimento das propostas vão ao encontro das necessidades das participantes na solução de situações/problemas, na qual cada uma é ao mesmo tempo autora, responsável pelas tomadas de decisões, uma vez que confeccionam os produtos e, algumas vezes ainda são as usuárias, para quem destinam suas próprias produções. Assim, as ferramentas de design funcionam mais como um modo de experimentar processos construtivos, de forma a compatibilizar interesses e necessidades pessoais e potencializar as habilidades das integrantes. Importante destacar também que o planejamento das atividades é processual e ocorre à medida que as oficinas acontecem, para que sejamos flexíveis com relação às questões que surgem ao longo do processo. Assim, as estudantes e os professores se reúnem com frequência para repensar as atividades, alinhar as expectativas, bem como analisar e avaliar as ações do projeto.

Além das oficinas, foram realizadas atividades de outras naturezas, também importantes como inspiração e ampliação de repertório artístico, como a visita à Companhia de Dança do Palácio das Artes de Belo Horizonte e as apresentações do projeto Flores do Morro na Escola de Arquitetura da UFMG e no Centro de Atividades Didáticas da UFMG. O grupo também realizou uma visita à Escola de Belas Artes da UFMG para participar de uma aula da disciplina Dança e Longevidade do Curso de Graduação/Licenciatura em Dança. Na mesma perspectiva, também exibimos o filme "Território do Brincar" (produção da Maria Farinha Filmes) com o intuito de iniciar o trabalho a partir das brincadeiras da infância e da cultura popular. Além disso, visitamos o Instituto Social Casa de Mãe, que dentre outras frentes de trabalho, possui um ateliê social para capacitação de mulheres em costura e estamparia e um ateliê aberto, que fomenta o empreendedorismo feminino. Essa visita teve grande impacto no nosso trabalho e tem servido de grande inspiração na produção e na busca pela sustentabilidade do grupo.

\section{Oficinas}

Nos primeiros encontros, trabalhamos com temas que pudessem fazer com que as participantes começassem a se expressar de forma mais livre e espontânea. Começamos com o tema das "linhas", algo muito familiar a elas no contexto do bordado, crochê e costura. A proposta surgiu, no entanto, para que as participantes se sentissem mais confiantes ao desenhar, fator essencial para possibilitar futuras criações de estampas e produtos. Lidar com o papel branco e o lápis, para muitas, sempre foi um grande desafio, fator que nos estimulou a debruçarmos mais sobre a técnica do desenho, utilizando ferramentas mais lúdicas, para que as participantes pudessem começar a criar registros mais autênticos e que seguissem uma identidade visual. Para integrar o Design, a Dança e Arquitetura, pensamos no significado da "linha" para as três áreas. Assim, fizemos diversas atividades nas quais criávamos linhas a partir das ligações dos nossos corpos e articulações - relacionados mais diretamente à dança - outras nas quais o movimento do corpo era responsável pelo registro gráfico, relacionando à dança e ao design - e outras de registros de trajetórias no espaço, que resultou como proposição final, a produção de um mapa afetivo do bairro - relacionando a dança, o design e a arquitetura. 
Figura 1 - Oficina de trajetórias, construção de um mapa afetivo, registrando os trajetos até o Flores

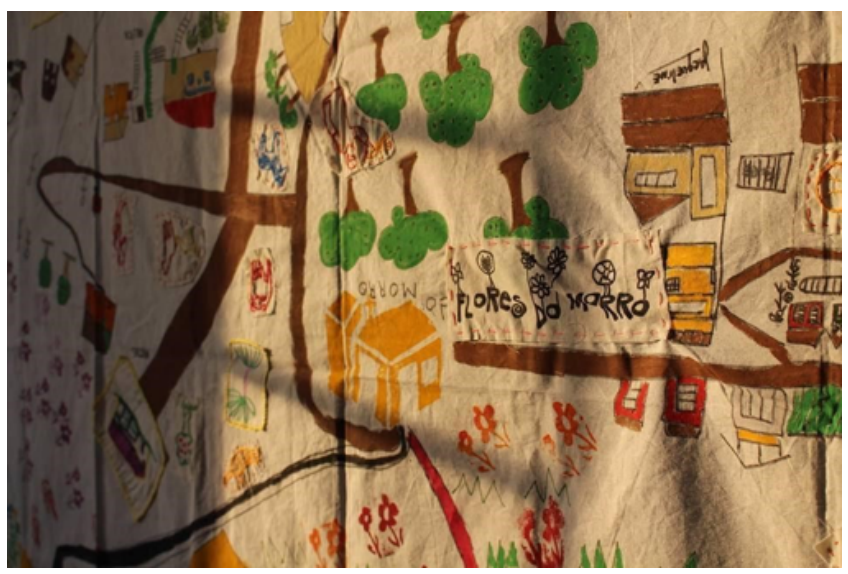

Fonte: acervo do grupo de pesquisa

Sob essa perspectiva de integração, desenvolvemos outros conceitos, como cor, forma, composição, simetria e modulação, que serviram de base para o trabalho. Na oficina de formas, fizemos algumas atividades mais abstratas, como a criação de figuras no espaço, com o uso do barbante; como também a criação de diferentes formas pelo uso de articulações do corpo, exercitando a nossa memória muscular (movimentos que o corpo grava depois de aprender); e atividades mais figurativas, como uma brincadeira com o jogo tangram e desenhos de observação.

Figura 2 - Oficina de formas, como o movimento do corpo influencia no traço

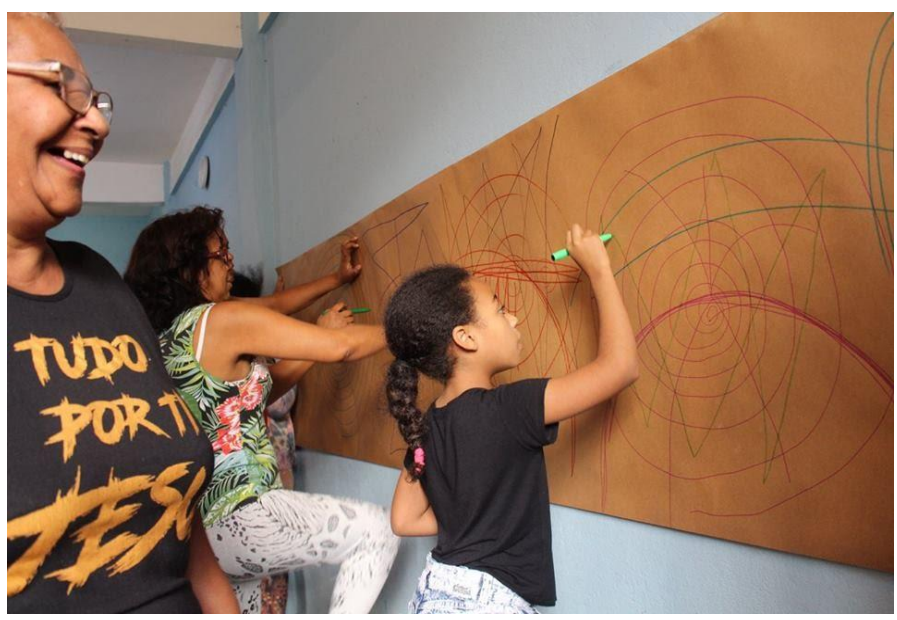

Fonte: acervo do grupo de pesquisa

$\mathrm{Na}$ oficina de cores, em um dos exercícios, a proposta era relacionar as cores frias aos movimentos mais lentos e cores quentes aos movimentos mais agitados. Depois, praticamos atividades lúdicas e interativas relacionadas ao círculo cromático. Por fim, para entendermos como se formam as cores, fizemos pinturas aquareladas apenas com cores primárias, além de um exercício de mistura de tinta a partir de movimentos corporais. 
Figura 3 - Oficina de cores, misturando as cores primárias a partir de movimentos corporais

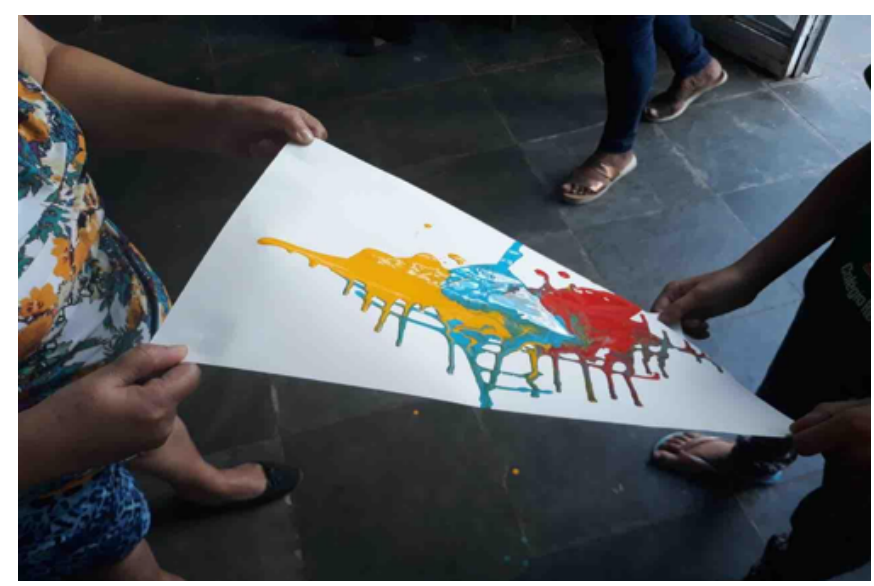

Fonte: acervo do grupo de pesquisa

Nas oficinas de desenho e síntese, trabalhamos com folhas de árvore que encontrávamos no caminho até o local do projeto, por ser um objeto palpável e de escala menor, suas formas de representação ficaram mais visíveis para as participantes. Dentre as várias atividades de desenho que realizamos até chegarmos nos estêncils, se destacam: contornar a folha da árvore, para ver o seu formato; passar o giz no papel, com a folha da árvore embaixo, para sentir a sua textura e desenhar os veios das folhas, para perceber como eles dão singularidade para o desenho.

Figura 4 - Oficina de síntese, criando estêncil

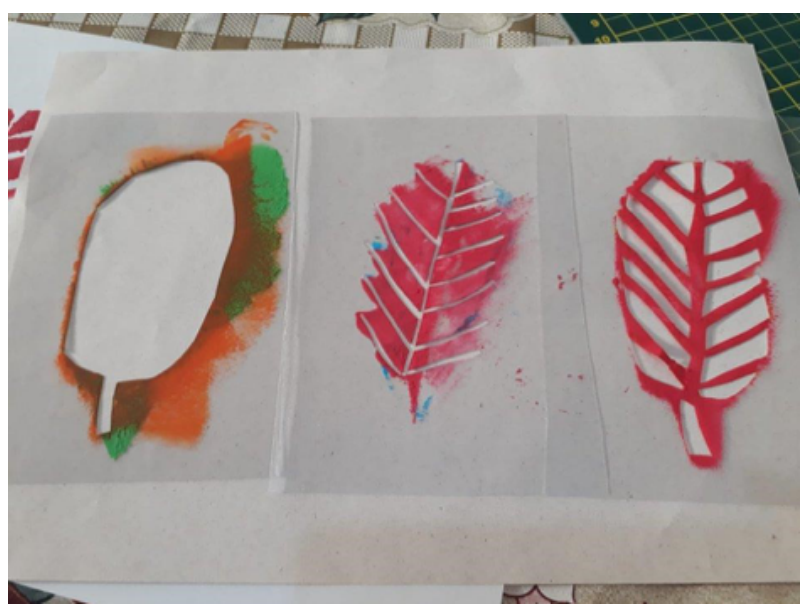

Fonte: acervo do grupo de pesquisa

Como ainda estávamos entendendo a demanda e o desejo real do grupo em comercializar os produtos, começamos propondo a produção de objetos que estávamos precisando no ambiente, como porta-trecos e organizadores. Posteriormente, fizemos objetos que cada uma produziria para si, como móbiles de origamis, suportes para copo, e porta-retratos. Importante dizer que, para cada produto, fizemos um trabalho integrado e interdisciplinar. 
Figura 5 - Construção de porta copos com tampinhas de garrafa e fuxicos de retalhos

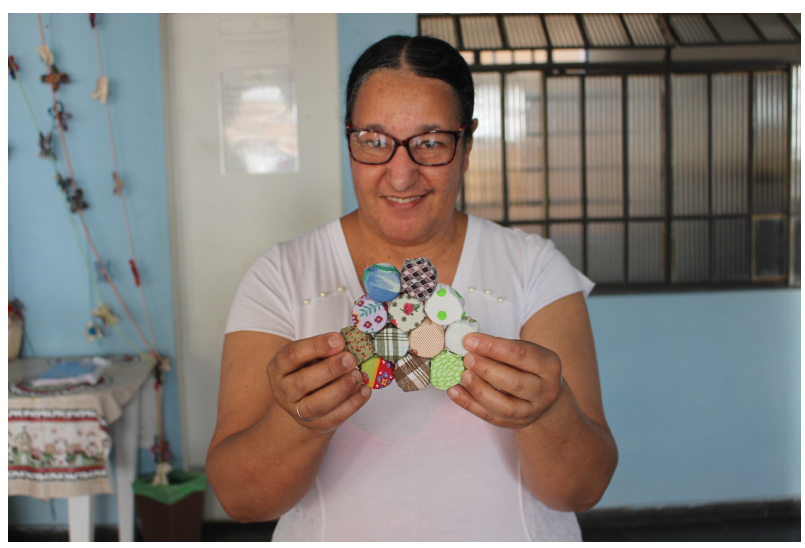

Fonte: acervo do grupo de pesquisa

Figura 6 - Oficina de composição, entendendo o processo de simetria e espelhamento
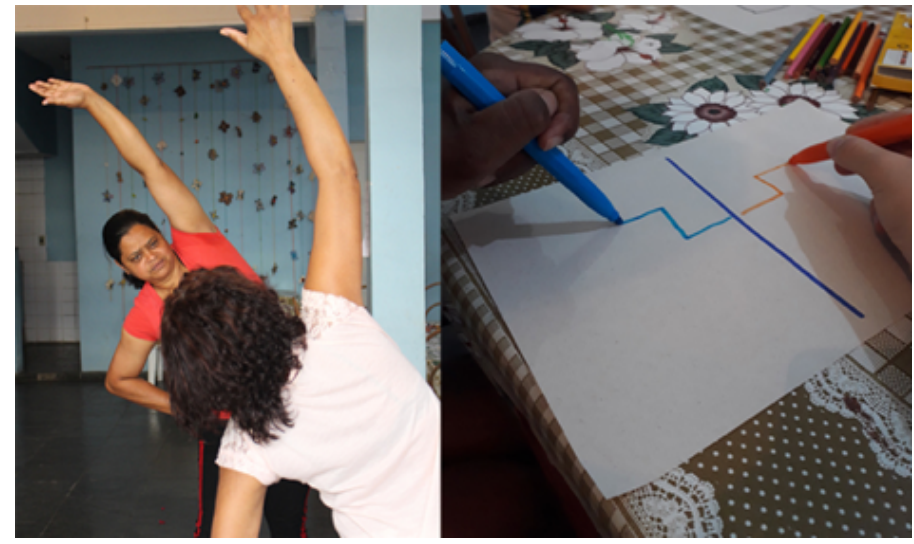

Fonte: acervo do grupo de pesquisa

Para fazer os mobiles, por exemplo, retomamos o tema das composições e das cores. Além disso, começamos com atividades com o corpo, que envolvem nossas "dobras" e articulações. Percebemos as "dobras" pequenas e grandes do corpo; dobramos e amassamos pedaços de papel com diferentes partes do corpo e comparamos os vincos no papel com as nossas rugas e cicatrizes. Depois disso, fizemos um trabalho com encaixes com os corpos e, finalmente, seguimos para o origami em si.

Já a partir dos porta-retratos, surgiu o tema das memórias. Compartilhamos muitas histórias pessoais, alegres e tristes, e resgatamos movimentos corporais de atividades que fazíamos no passado. Lembramos do movimento do corpo nas brincadeiras que gostávamos quando crianças ou em atividades que costumávamos fazer, como utilizar um tear ou trabalhar na roça. Também trabalhamos com fotos e fizemos interferências através do bordado. Antes disso, produzimos um porta-retratos com rolinhos de jornal e revista, para colocá-las.

Por fim, com o grupo mais engajado em uma produção, retomamos o trabalho com os estêncils das folhas de árvore, que havia funcionado muito bem anteriormente. Os primeiros produtos nos quais aplicamos a técnica, foram panos de prato, que muitas das mulheres já produziam paralelamente ao projeto. Estampamos as folhas em tecido americano cru, costuramos no pano de prato e finalizamos com bordado e crochê, técnicas que já eram ensinadas por voluntárias, antes do início do projeto de extensão. Assim, buscamos a integração das técnicas novas, propostas pelas estudantes, e as técnicas que elas já praticavam, o que contribui na criação 
de condições de potencialização de recursos e saberes locais e propõe o deslocamento do papel do designer, do arquiteto e do artista da dança como criadores ou detentores do saber para mediadores do processo de criação, aqueles que não apenas criam, mas potencializam situações em que a criatividade pode ser exercida por todos.

Figura 7 - Oficina de composição, com desenhos das silhuetas, após trabalho relacionado à memória

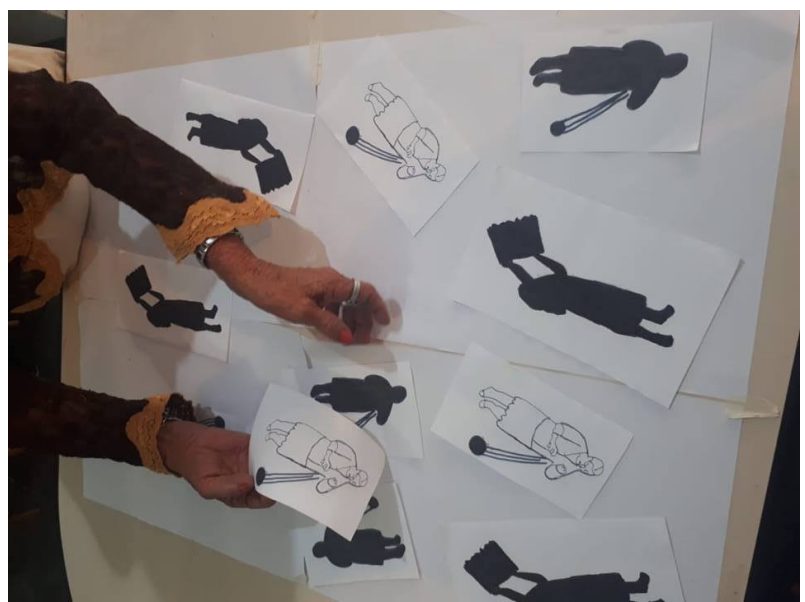

Fonte: acervo do grupo de pesquisa

Percebendo a real necessidade de sustentabilidade financeira do projeto e, satisfeitas com o resultado dos produtos, a possibilidade de venda ficou mais concreta e as participantes demonstraram esse desejo. Ao começarmos a produção dos panos de prato, algumas das participantes começaram a vislumbrar outros produtos e começaram a experimentar também jogos americanos, capas de almofada, saco de pão e ecobags, que foram os primeiros produtos a serem comercializados, além dos panos de prato.

Figura 8 - Pano de prato finalizado, com técnicas de estêncil, bordado e crochê

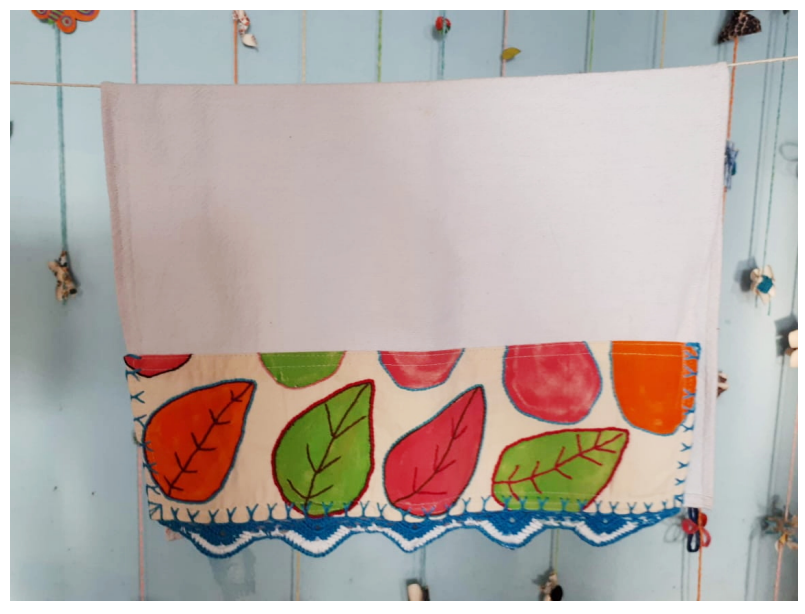

Fonte: acervo do grupo de pesquisa 
Figura 9 -Ecobag feita a partir de retalhos, técnicas de estêncil, bordado e etiqueta estampada com serigrafia

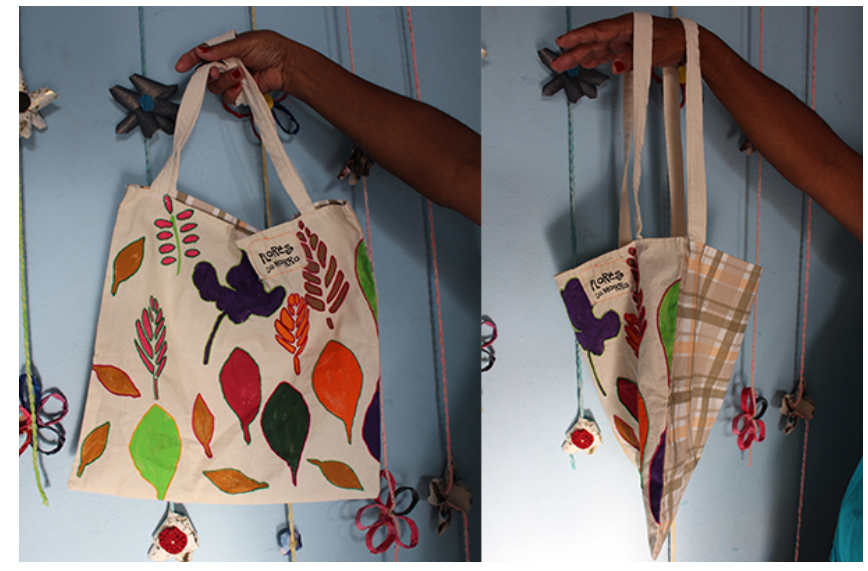

Fonte: acervo do grupo de pesquisa

Como resultados concretos das oficinas tem-se a produção e a realização de uma pequena feira em uma Igreja do bairro, bem como a venda dos produtos pelas redes sociais, encomendas de produtos, além de um espetáculo de dança no Museu das Minas e do Metal, a convite da produtora cultural Aldeia Jabuticaba, com remuneração para as participantes.

\section{Conclusão}

Ao refletir sobre as atividades realizadas durante o projeto e o impacto das ações no grupo e na comunidade, fica claro o papel da Universidade - pública, gratuita e de qualidade - na troca dos saberes produzidos dentro da academia com os saberes da comunidade. Como principais resultados, pode-se destacar a interação dialógica entre a Universidade e a comunidade, o fortalecimento da identidade do grupo e, principalmente, a melhoria da autoestima das participantes, facilmente percebida pelo seu envolvimento crescente.

Após um período de trabalho com as mulheres, elas passaram a ser mais propositivas, levando ideias de produtos e técnicas, e principalmente, se permitindo experimentar técnicas novas, o que no início era um grande desafio. Tem-se ouvido cada vez menos frases como "não sei desenhar" e "não sei dançar".

Algumas mulheres, que eram muito introspectivas, se mostraram, ao longo do processo, muito mais comunicativas, tanto na expressão artística, quanto na comunicação verbal. Além disso, todas passaram a participar mais das questões práticas do grupo, como também, passaram a ensinar umas às outras, de forma mais independente das voluntárias e das estudantes, o que reflete uma valorização do próprio trabalho e o fortalecimento das mulheres como coletivo. Ao ser questionada sobre a importância do projeto, Luci expôs: "Às vezes saio de casa triste e quando chego aqui é só alegria, e a gente esquece dos problemas." Segundo Ana Cristina: "Esse projeto está sendo bom para minha saúde". Para Jacqueline "a importância desse projeto vai desde a alegria do grupo, a forma como as pessoas lidam com as outras, me faz ficar mais feliz, com vontade de fazer as coisas. Esse projeto mudou muita coisa na minha vida, melhorei minha coordenação, melhorei meu humor, melhorei minha percepção".

Além do impacto social das ações do projeto no grupo e na comunidade, percebe-se o impacto também na formação das estudantes envolvidas, que tiveram a oportunidade de colocar em prática os conhecimentos adquiridos na Universidade e puderam ter acesso a outros tipos de saberes e outras realidades, vivenciando na prática as potencialidades desse tipo de ação. 
Para todos os encontros com o grupo, foram feitos relatos escritos, contendo as atividades planejadas, a avaliação sobre o processo das atividades realizadas e os resultados alcançados. Além disso, também realizamos registros fotográficos e em vídeo das atividades das oficinas, bem como postagens nas páginas das redes sociais do projeto.

Esse projeto foi premiado na "Semana do Conhecimento 2018", da UFMG, como destaque na categoria "Trabalho". Essa premiação, que levou muitas mulheres do grupo ao palco pela primeira vez, foi muito importante como reconhecimento do projeto e serviu de inspiração ao grupo na continuidade das atividades.

De uma certa forma, podemos dizer que o lugar mais importante para nós nesse trabalho foi o território sensível do encontro. Um espaço em que cada qual aprende com o outro, e que de ambos faz brotar uma criação, um fazer que é de cada um e de todos, um "um espaço de presença [...]", como nos diz Henri Maldiney (2007, p. 167), de singulares presenças.

Também por isso, o que prima nesse trabalho é a disponibilidade para o inesperado, a escuta, a observação respeitosa, o não saber. Como nos ensina Guattari:

\footnotetext{
O encontro não desenha a distância que nos separa, mas o entrelaçamento de nossas singularidades. Uma vez que somos obrigados, por função, a cuidar dos outros, dar "assistência", uma espécie de relação asséptica sadomasoquista se instaura, o que polui abordagens profundas aparentemente mais inocentes e mais desinteressadas (GUATTARI, 1977, p.172, tradução nossa).
}

Acreditamos que estamos construindo, junto a essas mulheres, um território de presença, um espaço no qual cada uma pode-ser ${ }^{3}$ um espaço potencial e de potencialidades em emergência.

\section{Agradecimentos}

Agradecemos às Pró-Reitorias de Extensão e de Graduação da Universidade Federal de Minas Gerais pelo apoio ao projeto e pelas bolsas de extensão concedidas às estudantes. Um agradecimento especial às estudantes voluntárias que tanto contribuem com o projeto.

\section{Referências}

FREIRE, Paulo. Pedagogia da autonomia: saberes necessários à prática pedagógica. Rio de Janeiro: Paz e Terra, 2016.

GUATTARI, Félix. La révolution moléculaire. Fontenay-sous-Bois, Recherches, 1977.

KRUCKEN, Lia. Design e Território - Valorização de identidades e produtos locais. São Paulo: Studio Nobel, 2009.

LANGENBACH, Marcos Lins. Além do apenas funcional: inovação social e design de serviços na realidade brasileira. Dissertação. Mestrado em Engenharia de Produção, Universidade Federal do Rio de Janeiro, Rio de Janeiro, 2008.

MALDINEY, Henri. Penser l'homme et la psychose. Grenoble: Edition Jérôme Millon. 2007.

MANZINI, Ezio. Design para a inovação social e sustentabilidade: comunidades criativas, organizações colaborativas e novas redes projetuais. Rio de Janeiro: E-Papers, 2008.

SENNETT, Richard. O Artífice. Rio de Janeiro: Record, 2009.

VIANNA, Klauss. A Dança - Klauss Vianna: em colaboração com Marco Antônio de Carvalho; São Paulo, Editora Summus, 2005.

\footnotetext{
${ }^{3}$ Termo utilizado por Henri Maldiney.
} 